\section{Late effects of blood and marrow transplantation}

We appreciated Inamoto and Lee's thoughtful review summarizing the late effects of hematopoietic stem cell transplantation (HCT), ${ }^{1}$ particularly their dual emphasis on both the prevention and treatment of potential complications. In the interest of broadening the scope of their review, we wish to draw attention to two additional and frequently overlooked complications of HCT: female sexuality and financial toxicity.

Inamoto and Lee mention testosterone replacement as a potential treatment for sexual dysfunction in male HCT recipients, but do not address these symptoms in female patients. Psychosexual dysfunction is common in female HCT recipients, an effect mediated both by chemotherapy-related neurohormonal toxicities and also by unique considerations such as vulvovaginal graft-versus-host disease (GvHD) and therapy-related negative body image (e.g., related to chronic corticosteroid use). ${ }^{2}$ Specific preventative steps in female HCT recipients, in addition to consideration of hormone replacement therapy for premature ovarian failure as discussed by Inamoto and Lee, should include annual gynecologic exams ${ }^{3}$ as well as prompt gynecological consultation should symptoms develop. ${ }^{4}$ Non-medicinal interventions to reduce sexual dysfunction in female HCT recipients include communication training, behavioral strategies, and use of vaginal lubrication. ${ }^{2}$ Treatment modalities for patients with vulvovaginal GvHD include topical estrogen, topical glucocorticoids, topical cyclosporine, and insertion of vaginal dilators. ${ }^{5}$

Inamoto and Lee's review also does not mention nonmedical toxicities of HCT; for example, caregiver burnout and financial distress. The financial toxicities of transplant vary widely among patients based on transplant type and conditioning, transplant center and country, insurance status if applicable, and post-transplant clinical course. ${ }^{6}$ Even among patients with health insurance, around half of HCT survivors suffer from post-transplant financial hardships. ${ }^{7,8}$ While no easy solutions are available, increased cost transparency and advance financial planning for patients may be helpful to prevent catastrophic events such as bankruptcy or loss of domicile..$^{, 10}$

These toxicities may be uncomfortable for providers or patients to discuss but, for HCT recipients and their loved ones, they can have persistent and significant effects. In addition to adopting the excellent guidance for
post-HCT complications compiled by Inamoto and Lee, we encourage providers to remain vigilant for these and other survivorship challenges that may go under-recognized.

Rahul Banerjee, ${ }^{1}$ Marlise R. Luskin ${ }^{2}$ and Alison W. Loren ${ }^{3}$

${ }^{1}$ Department of Medicine, Perelman School of Medicine of the University of Pennsylvania, Philadelphia, PA; ${ }^{2}$ Department of Medical Oncology, Dana-Farber Cancer Institute, Boston, MA and ${ }^{3}$ Division of Hematology/Oncology, Department of Medicine, Perelman School of Medicine of the University of Pennsylvania, Philadelphia, PA, USA

Correspondence: rahul.banerjee.md@gmail.com doi:10.3324/haematol.2017.176289

Information on authorship, contributions, and financial 2 other disclosures was provided by the authors and is available with the online version of this article at wWw. haematologica.org.

\section{References}

1. Inamoto Y, Lee SJ. Late effects of blood and marrow transplantation. Haematologica. 2017;102(4):614-625.

2. Thygesen KH, Schjødt I, Jarden M. The impact of hematopoietic stem cell transplantation on sexuality: a systematic review of the literature. Bone Marrow Transplant. 2012;47(5):716-724.

3. Syrjala KL, Martin PJ, Lee SJ. Delivering care to long-term adult survivors of hematopoietic cell transplantation. J Clin Oncol. 2002;30(30):3746-3751

4. Chung CP, Sargent RE, Chung NT, et al. Graft-versus-host disease associated vulvovaginal symptoms after bone marrow transplantation. Biol Blood Marrow Transplant. 2016;22(2):378-379.

5. Zantomio D, Grigg AP, MacGregor L, et al. Female genital tract graftversus-host disease: incidence, risk factors, and recommendations for management. Bone Marrow Transplant. 2006;38(8):567-572.

6. Khera N, Zeliadt SB, Lee SJ. Economics of hematopoietic cell transplantation. Blood. 2012;120(8):1545-1551.

7. Khera N, Chang Y, Hashmi S, et al. Financial burden in recipients of allogeneic hematopoietic cell transplantation. Biol Blood Marrow Transplant. 2014;20(9):1375-1381.

8. Abel GA, Albelda R, Khera N, et al. Financial hardship and patientreported outcomes after hematopoietic cell transplantation. Biol Blood Marrow Transplant. 2016;22(8):1504-1510.

9. Farnia S, Ganetsky A, Silver A, et al. Challenges around access to and cost of life-saving medications after allogeneic hematopoietic cell transplantation for Medicare patients. Biol Blood Marrow Transplant. 2017;23(8):1387-1392.

10. Kim W, McNulty J, Chang YH, et al. Financial burden after allogeneic hematopoietic cell transplantation: a qualitative analysis from the patient's perspective. Bone Marrow Transplant. 2015;50(9):12591261. 